\title{
Ionic Liquids as Active Pharmaceutical Ingredients
}

\author{
Ricardo Ferraz, ${ }^{*[a, b]}$ Luís C. Branco, ${ }^{[b]}$ Cristina Prudêncio, ${ }^{[a, c]}$ João Paulo Noronha, ${ }^{[b]}$ and \\ Željko Petrovski ${ }^{* b]}$
}

\begin{abstract}
Ionic liquids (ILs) are ionic compounds that possess a melting temperature below $100^{\circ} \mathrm{C}$. Their physical and chemical properties are attractive for various applications. Several organic materials that are now classified as ionic liquids were described as far back as the mid-19th century. The search for new and different ILs has led to the progressive development and application of three generations of ILs: 1) The focus of the first generation was mainly on their unique intrinsic physical and chemical properties, such as density, viscosity, conductivity, solubility, and high thermal and chemical stability. 2) The second generation of ILs offered the potential to tune some of these physical and chemical properties, allowing the formation of "task-spe-
\end{abstract}

cific ionic liquids" which can have application as lubricants, energetic materials (in the case of selective separation and extraction processes), and as more environmentally friendly (greener) reaction solvents, among others. 3) The third and most recent generation of ILs involve active pharmaceutical ingredients (API), which are being used to produce ILs with biological activity. Herein we summarize recent developments in the area of third-generation ionic liquids that are being used as APIs, with a particular focus on efforts to overcome current hurdles encountered by APIs. We also offer some innovative solutions in new medical treatment and delivery options.

\section{Introduction}

Ionic liquids (ILs) have been a topic of great interest since the mid-1990s. ${ }^{[1]}$ They have attracted particularly high attention in recent years; approximately 1800 papers were published in the area of ILs in 2008 alone, ${ }^{[2]}$ documenting a variety of new IL applications. The range of IL uses had been broadened, and there was a significant increase in the scope of both physical and chemical IL properties. ${ }^{[3,4]}$

ILs are generally defined as organic salts with melting points below $100^{\circ} \mathrm{C}$ (some of them are liquid at room temperature) and composed entirely of ions. ${ }^{[2,4-6]}$ Despite the fact that ILS were first reported in the mid-1800s, widespread interest in this compound class has occurred only recently. ILs have come under worldwide scrutiny mainly through their use as solvents. $^{[2,4,7,8]}$ In particular, the room temperature ionic liquids (RTILs), also known as "designer solvents" (because it is possible to create an IL with a given required property), have served as greener alternatives to conventional toxic organic solvents..$^{[2,7,9]}$ RTILs have been used for several other applications, and their development continues at a considerable rate owing to their peculiar physical and chemical properties such as high thermal and chemical stability, lack of inflammability, low volatility, and tunable solubility with several organic compounds. By taking advantage of their unique properties, ${ }^{[2,10]}$ several IL applications have been described, including reaction media for many organic transformations ${ }_{1}^{[2,11]}$ in separations and extractions, ${ }^{[2,12]}$ as electrolytes for electrochemistry, ${ }_{1}^{[2,13]}$ in nanotechnology, ${ }_{1}^{[2,14]}$ in biotechnology, ${ }^{[2,15]}$ and in engineering processes, ${ }^{[2,16]}$ among others.

ILs can be grouped into three generations according to their properties and characteristics. ${ }^{[17]}$ The first generation includes ILs for which the accessible physical properties such as decreased vapor pressure and high thermal stability ${ }^{[18]}$ are often unique (Figure 1, 1st Generation). Second-generation ILs have potential use as functional materials such as energetic materials, lubricants, and metal ion complexing agents, (Figure 1, 2nd Generation). By taking advantage of their tunable physical and chemical properties, ILs can produce a remarkable platform on which-at least potentially-the properties of both cation and anion can be independently modified and designed to enable the production of new useful materials while maintaining the main properties of an IL. Some RTILs have been used as reaction media to produce or improve the preparation of various pharmaceuticals. ${ }^{[7,19,20]}$ Recently, the third generation of ILs ${ }^{[17]}$ (Figure 1, 3rd Generation) has been described using active pharmaceutical ingredients (APIs) to produce ILs with biological activity.

While a tremendous amount of research has focused on the physical and chemical properties of ILs, more recently the toxicity and biological behavior of ILs have been included as two

\section{[a] R. Ferraz, Prof. C. Prudêncio}

Ciências Químicas e das Biomoléculas

Escola Superior de Tecnologia da Saúde do Porto do Instituto Politécnico do Porto

Rua Valente Perfeito 322, 4400-330, Vila Nova de Gaia (Portugal)

Fax: (+ 351) 22-206-1001

E-mail: ricardoferraz@eu.ipp.pt

[b] R. Ferraz, Dr. L. C. Branco, Prof. J. P. Noronha, Dr. Ž. Petrovski Departamento de Química, REQUIMTE-CQFB

Faculdade de Ciências e Tecnologia da Universidade Nova de Lisboa 2829-516 Caparica (Portugal)

Fax: (+351)-21-294-8550

E-mail:zeljko.petrovski@dq.fct.unl.pt

[c] Prof. C. Prudêncio

Centro de Farmacologia e Biopatologia Química (U38-FCT)

Faculdade de Medicina da Universidade do Porto

Alameda Prof. Hernâni Monteiro, 4200-319 Porto (Portugal) 


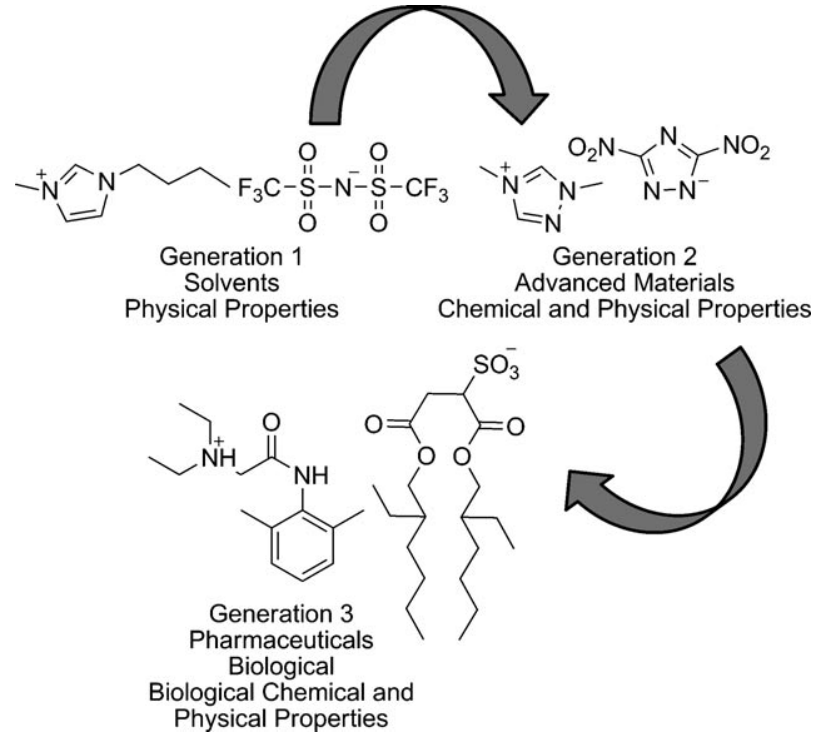

Figure 1. The scientific evolution of ILs, from unique physical properties (Generation 1) through the combination of chemical and physical properties (Generation 2), to the more recent studies of their biological and pharmaceutical activities (Generation 3) [adapted from Hough et al]. ${ }^{[17]}$

of the most highly debated topics in this field. Biologically active ions have been used to develop novel ILs; however, the primary drive behind the research into these materials has been focused on the use of well-known low-toxicity ions to obtain ILs with the desired set of properties. ${ }^{[17,21,22]}$

\section{Historical perspective}

The first ionic liquid was described as "red oil" and was produced in the course of Friedel-Crafts reactions carried out in the mid-19th century. However, the composition of this red oil was only lately identified as a salt. For $\mathrm{AlCl}_{3}$-catalyzed reactions, the structure proposed for this liquid was the heptachlorodialuminate salt shown in Figure 2. This IL as red oil, along with

$$
\overbrace{1}^{\mathrm{R}} \mathrm{Al}_{2}^{-} \mathrm{Cl}_{7} \widehat{N}_{2}^{+} \mathrm{NH}_{3} \overline{N O}_{3}
$$

Figure 2. The structure proposed for the heptachlorodialuminate salt intermediate $\mathbf{1}$ in the Friedel-Crafts reactions. An example of alkylammonium nitrates: ethylammonium nitrate (2).

more complicated structures, were patented as useful materials, but no industrial application has been reported. ${ }^{[7,23]}$

Modern ILs are quite different from those of the beginning of the 20th century, such as the alkylammonium nitrates 2, shown in Figure $2 .{ }^{[23]}$ The most common ILs containing quaternary heterocyclic cations (such as alkylpyridinium or dialkylimidazolium) and inorganic anions have an ancestry traceable to traditional high-temperature molten salts. ${ }^{[23]}$ The inorganic chloroaluminates are considered examples of salts between the truly high-temperature molten salts (such as cryolite or $\mathrm{LiCl}-\mathrm{KCl}$ ) and the current ionic liquids.

The history behind the alkali chloroaluminate molten salts is a good example of fundamental research emerging rather quickly into practical application. In an example case, researchers at the United States Air Force Academy (Colorado Springs, CO, USA) picked up on work carried out by Frank Hurley and Thomas Wier ${ }^{[24]}$ on electrodeposition of aluminum using $\mathrm{AlCl}_{3}-$ based molten salts. This led to the development of electrolytes for thermal batteries based on mixtures of $\mathrm{AlCl}_{3}$ and 1-ethylpyridinium halides, mainly the bromide (Figure 3 ).

One of most important breakthroughs in the history of ILs is related to the discovery of the 1-butylpyridinium chloride-aluminum chloride mixture (BPC-AlCl ${ }_{3}$ Figure 4). ${ }^{[25]}$ This allchloride system represented a substantial improvement over the mixed bromide-chloride ionic liquids, ${ }^{[25]}$ but had some disadvantages; this lead to new research and developments that brought forth the water-stable ionic liquids. ${ }^{[23,26]}$

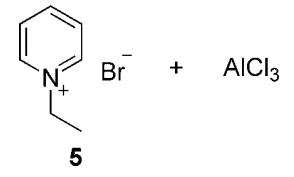

Figure 3. Mixture of $\mathrm{AlCl}_{3}$ and 1-ethylpyridinium bromide (5).

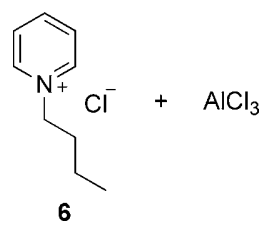

Figure 4. 1-Butylpyridinium chloride (6) and aluminum chloride mixture (BPC- $\left.\mathrm{AlCl}_{3}\right)$.
The research for novel water-soluble ILs was described by Fuller et al. ${ }^{[27]}$ using a series of ILs from the traditional dialkylimidazolium cations combined with different anions (tetrafluoroborate, hexafluorophosphate, nitrate, acetate, and sulfate) along with the additional series of mostly larger anions (Figure 5). Over the years, new classes of cations and anions

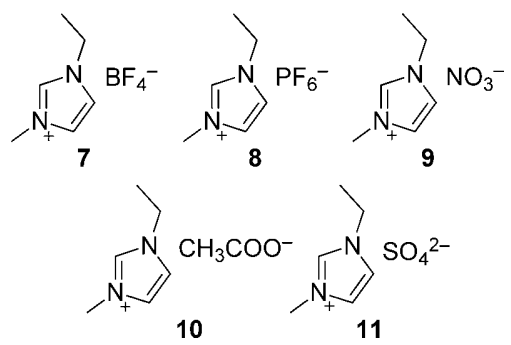

Figure 5. Tetrafluoroborate (7), hexafluorophosphate (8), nitrate (9), acetate salts (10), and sulfate (11) as anions combined with 1-ethyl-2-methylimidazolium cation ILs.

have been reported. ${ }^{[2]}$ Because ILs are intrinsically safer than highly volatile and flammable organic solvents, their use as solvents improves the safety margins and environmental performance in solution chemistry. ${ }^{[4]}$ Nowadays, the interest from disciplines outside chemistry and engineering is growing. Recent IL applications include use in sensors, solar cells, and solidstate photocells and batteries, as well as thermal fluids, lubricants, hydraulic fluids, and ionogels. ILs are indeed tunable, multipurpose materials for a variety of applications. ${ }^{[6]}$ 
Finally, the particular interest in ILs from the biological and pharmaceutical sciences is not only for use as reaction media, but as pharmaceutical solvents or co-solvents for the delivery of drugs with poor water solubility. ${ }^{[28]}$ They are also applied in micro-emulsion systems, which can facilitate the dissolution of drugs that are insoluble or poorly soluble in water. Some IL micro-emulsions can be used as modern colloidal carriers for topical and transdermal delivery, while other IL systems have been used as entrapped/solubilized drug reservoirs for controlled release. ${ }^{[29]}$

\section{ILs as Active Pharmaceutical Ingredients (APIs)}

\section{Ionic pharmaceuticals and the polymorphism problem}

The pharmaceutical industry is unquestionably facing a series of challenges. While many of these challenges are related to the features of this industry and present business models, there is also an urgent need for new scientific advances that yield innovative and effective drugs and therapies. The classical strategies currently being followed are reaching the point at which it is difficult to come up with effective and acceptable new chemical entities. Very few drugs $(<10 \%)$ that are evaluated in clinical tests make it to the market, decreasing the accessibility of efficient therapies for the people who need them. ${ }^{\text {[30] }}$

Roughly $50 \%$ of available drugs are administrated as salts. The physicochemical and biopharmaceutical properties of a given drug can be finely tuned by pairing with various counterions. From a pharmaceutical point of view, the melting temperature and solubility are relevant parameters because of their routine measurement and due to their potential influence on drug processing and bioavailability. ${ }^{[31]}$ This is an easy way to adjust the properties of a drug with ionizable functional groups to overcome undesirable features present in the parent drug. ${ }^{[32]}$ The quality, safety, and performance of a drug are related to the salt structure. The selected ion pair can significantly influence the pharmacokinetics of a drug candidate. This is one of the reasons why regulatory authorities have begun to classify novel salts of a registered drug as a new chemical entity.

The development of salts of the targeted active compounds is a suitable and well-known approach to overcome the limitations faced by the pharmaceutical industry. In spite of this, cocrystals, amorphous forms, and polymer-embedded pharmaceuticals have been tested in order to solve such classical problems as spontaneous polymorphic transformation of crystalline drug forms; this can pose significant problems for drug designers, and can convert an effective dose into a lethal dose by altering the solubility of the active ingredient. ${ }^{[30]}$ Pure compounds, salts, and all kinds of pharmaceuticals and drug candidates can suffer polymorphism (Figure 6), and there are no means to predict the emergence of polymorphism in any given compound despite recent efforts toward a better understanding of crystal polymorphism in pharmaceutical compounds. ${ }^{[33-35]}$

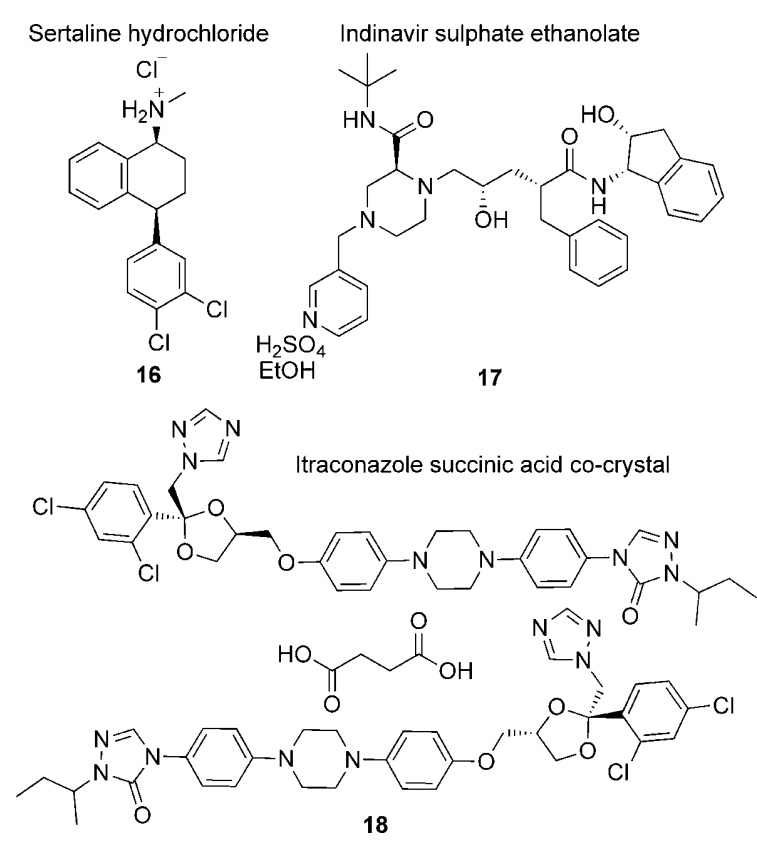

Figure 6. Examples of the types of crystal forms of pharmaceutical compounds that can have problems with polymorphism.

The cost of a pharmaceutical product is depends directly on crystal polymorphism and solvation state. This situation has been illustrated by costly product failures and protracted patent litigation. For example, the case of the Norvir capsule product failure in 1998 was recounted and rationalized by solving the crystal structures of the Ritonavir polymorphs. ${ }^{[36]}$ In theory, all solid drugs are susceptible to unpredictable polymorph formation. An unexpected metastable form of 5-fluorouracil (a well-known drug) was described as a new polymorphic structure. ${ }^{[33,37]}$ The use of initial generic versions of some relevant drugs has been permitted based on patently different yet pharmaceutically equivalent polymorphs (or hydrates), which in some cases have led to legal disputes. ${ }^{[33]}$ Academic researchers are currently working with both experimental (engineering) and theoretical (prediction) insight into crystal forms. ${ }^{[35]}$

The pharmaceutical industry should be open to the potential benefits that crystal engineering can offer, but it also has to be aware of other forms. Drug companies mainly rely on solid, primarily crystalline forms for the delivery of APIs for reasons of purity, thermal stability, manufacturability, and ease of handling. In contrast, liquid drug formulations are much less common, and are usually based on eutectic mixtures. ${ }^{[38,39]}$ However, problems associated with the solid form of many drugs have been consistently reported; issues include polymorphic conversion, low solubility, low bioavailability for crystalline solids, and the tendency of amorphous forms to spontaneously crystallize. For these reasons, and also due to considerable financial interests brought about by legal ramifications, screening for new drug forms, including salts, solvates, and cocrystals is a continuous pursuit. ${ }^{[33,39]}$ Therefore, the use of an active drug in liquid form can avoid some of polymorphism problems associated with solids. Other similar approaches 
have been developed with liquid drug formulations prepared as eutectic mixtures, ${ }^{[39,40]}$ but these can dilute the APIs owing to large quantities of inactive ballast in the formulation. In this light, pure liquid-phase APIs would provide new perspectives for drug delivery and treatment approaches.

From the point of view of the pharmaceutical industry, the use of liquid salts is relevant, preferably those with melting points below room temperature. Some synthetic strategies that have been employed to decrease the melting point of the salts include selection of cations with a low tendency to crystallize, or ions with a more diffuse charge. For example, 3ethyl-1-methylimidazolium chloride is an organic salt with a melting point of $77-79^{\circ} \mathrm{C}$ that can be lowered to $-21^{\circ} \mathrm{C}$ by simple replacement of the chloride with a dicyanamide anion. ${ }^{[39,41]}$

\section{Pharmaceutical activity}

The question of IL toxicity has delayed the entry of ILs into the biosciences. The toxicities observed toward microorganisms and cell cultures cover a wide range of biocidal potencies, from those of rather inactive molecular solvents such as ethanol or dimethyl sulfoxide, which are biocompatible to very high aqueous concentrations, to highly active biocides. The latter have even led to the proposal for the use of some ionic liquids as wood preservatives and in a variety of other pharmaceutical applications $^{[39,42]}$ (Figure 7). The number of publications report-

ing antimicrobial activity for ILs is growing, and this could be very interesting for the development of new bioactive materi-

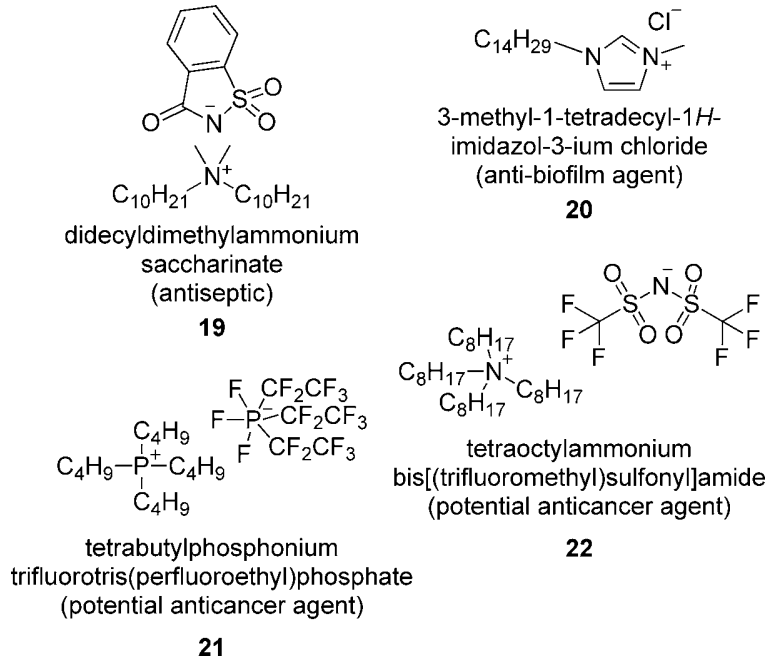

Figure 7. Some examples of ILs and their application.

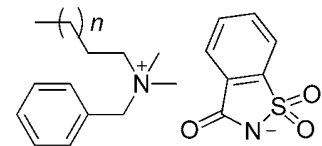

[BA][Sac]

$n=9(60 \%)$ and $n=11(40 \%)$

23

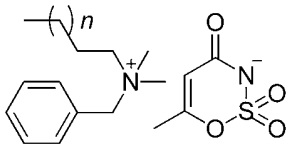

[BA][Ace]

$n=11(40 \%)$

24
Figure 8. Examples of antibacterial agents.

als as antiseptics, ${ }^{[39,43-45]}$ for example (Figure 8). Table 1 and Table 2 list some examples of antimicrobial activity (minimum inhibitory concentration and minimum bactericidal or fungici-
Table 1. Minimum inhibitory concentrations for various ILs and starting salts.

\begin{tabular}{|c|c|c|c|c|c|c|}
\hline \multirow[b]{2}{*}{ Strain } & \multirow[b]{2}{*}[\mathrm{BA}]{$[\mathrm{Sac}](23)^{[\mathrm{b}]}$} & \multirow[b]{2}{*}[\mathrm{DDA}]{$[\mathrm{Sac}](19)^{[\mathrm{c}]}$} & \multicolumn{2}{|c|}{$\mathrm{MIC}[p p m]^{[\mathrm{a}]}$} & \multirow[b]{2}{*}[\mathrm{BA}]{$[\mathrm{Cl}]^{[f]}$} & \multirow[b]{2}{*}[\mathrm{DDA}]{$[\mathrm{Cl}]^{[\mathrm{f}]}$} \\
\hline & & & {$[B A][$ Ace $](24)^{[d]}$} & {$[\mathrm{DDA}][$ Ace $](25)^{[\mathrm{e}]}$} & & \\
\hline S. aureus & 4 & 4 & 4 & 8 & 2 & 2 \\
\hline S. aureus (MRSA) & 4 & 4 & 4 & 4 & 2 & 2 \\
\hline E. faecium & 8 & 8 & 8 & 8 & 4 & 4 \\
\hline E. coli & 16 & 16 & 31 & 16 & 8 & 8 \\
\hline M. luteus & 8 & 4 & 8 & 8 & 4 & 2 \\
\hline S. epidermidis & 4 & 4 & 4 & 4 & 2 & 2 \\
\hline K. pneumoniae & 4 & 4 & 8 & 4 & 4 & 4 \\
\hline C. albicans & 16 & 16 & 16 & 16 & 8 & 8 \\
\hline R. rubra & 16 & 16 & 16 & 16 & 8 & 4 \\
\hline S. mutans & 0.1 & 31 & 1 & 16 & 2 & 2 \\
\hline
\end{tabular}

[a] Lowest compound concentration that inhibits visible growth of a microorganism after overnight incubation. [b] Benzalkonium saccharinate. [c] Didecyldimethylammonium saccharinate. [d] Benzalkonium acesulfamate. [e] Didecyldimethylammonium acesulfamate. [f] Starting salts: benzalkonium chloride ([BA][CI]) and didecyldimethylammonium chloride ([DDA][CI]); data from Hough-Troutman et al.. ${ }^{[43]}$ listed for comparison.

dal concentration, respectively) observed for ILs based on ammonium and benzalkonium cations combined with saccharinate and acesulfamate anions. These results demonstrate the potential use of ILs, in particular, against Streptococcus mutans. ILs could even be used as potential anticancer agents ${ }^{[22,39,46,47]}$ (Figure 9 and Table 3). Recently the anti-biofilm activity of some ILs and their reported potent, broad-spectrum activity against a variety of clinically significant microbial pathogens, including methicillin-resistant Staphylococcus aureus (MRSA), ${ }^{[39]}$ have been investigated ${ }^{[45]}$ (Figure 10 and Table 4).

Microbial biofilms are everywhere in nature and represent the dominant mode of microorganism growth. Various types of bacteria, such as MRSA, are observed in colonies adherent to material surfaces. These colonies often form coatings, known as biofilms. A common feature of biofilm communities is their tendency to exhibit significant tolerance and resistance to antibiotics and antimicrobial or biocidal challenge, relative to planktonic bacteria of the same species. ${ }^{[45]}$ One of the attractions of ionic liquids in this regard is the possibility to tailor their physical, chemical, and biological properties by building specific features into the chemical structures of the cation 
Table 2. The minimum bactericidal or fungicidal concentrations for various ILs and starting salts.

\begin{tabular}{|c|c|c|c|c|c|c|}
\hline \multirow[b]{2}{*}{ Strain } & \multirow[b]{2}{*}[\mathrm{BA}]{$[\mathrm{Sac}](23)^{[\mathrm{b}]}$} & \multirow[b]{2}{*}[\mathrm{DDA}]{$[\mathrm{Sac}](19)^{[\mathrm{c}]}$} & \multicolumn{2}{|c|}{ MIC $[p p m]^{[\mathrm{a}]}$} & \multirow[b]{2}{*}[\mathrm{BA}]{$[\mathrm{Cl}]^{[\mathrm{f}]}$} & \multirow[b]{2}{*}[\mathrm{DDA}]{$[\mathrm{Cl}]^{[\mathrm{ff}]}$} \\
\hline & & & {$[B A][$ Ace $](24)^{[d]}$} & {$[\mathrm{DDA}][$ Ace $](25)^{[\mathrm{e}]}$} & & \\
\hline S. aureus & 31.2 & 62.5 & 31.2 & 16 & 62.5 & 31.2 \\
\hline S. aureus (MRSA) & 31.2 & 31.2 & 31.2 & 31.2 & 31.2 & 31.2 \\
\hline E. faecium & 16 & 16 & 31.2 & 31.2 & 31.2 & 31.2 \\
\hline E. coli & 62.5 & 16 & 125 & 62.5 & 62.5 & 31.2 \\
\hline M. luteus & 62.5 & 31.2 & 62.5 & 62.5 & 31.2 & 31.2 \\
\hline S. epidermidis & 31.2 & 16 & 62.5 & 31.2 & 16 & 31.2 \\
\hline K. pneumoniae & 62.5 & 16 & 31.2 & 31.2 & 31.2 & 16 \\
\hline C. albicans & 31.2 & 16 & 31.2 & 31.2 & 16 & 16 \\
\hline R. rubra & 62.5 & 31.2 & 62.5 & 62.5 & 31.2 & 31.2 \\
\hline S. mutans & 0.5 & 62.5 & 16 & 125 & 16 & 16 \\
\hline
\end{tabular}

[a] Lowest compound concentration required to kill a microorganism. [b] Benzalkonium saccharinate. [c] Didecyldimethylammonium saccharinate. [d] Benzalkonium acesulfamate. [e] Didecyldimethylammonium acesulfamate. [f] Starting salts: benzalkonium chloride $([\mathrm{BA}][\mathrm{Cl}])$ and didecyldimethylammonium chloride ([DDA][CI]); data from Hough-Troutman et al., ${ }^{[43]}$ listed for comparison.

the latter is an anion with a sweet taste (compound 19, Figure 7). Indeed, the frequent designation of "designer solvents" for ILs might be easily adapted for IL "designer drugs," as physical, chemical, and biological properties of a drug can be tuned by choice of counterion rather than by covalent modification.

Some compounds have difficulty penetrating biological membranes because they are very hydrophilic. The correct arrangement between an active ion with another more lipophilic character could offer a solution

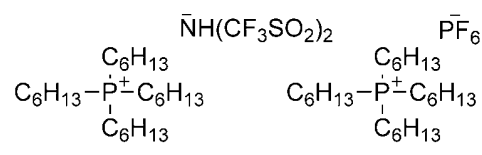

26

27

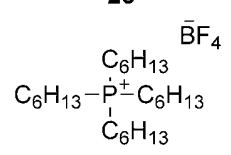

28

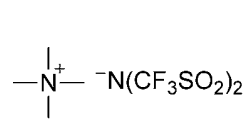

30

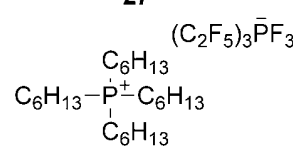

29<smiles>CC[N+](CC)(CC)Cc1ccccc1</smiles>

Figure 9. Examples of potential anticancer agents. ${ }^{[46]}$

$$
\begin{aligned}
& \underbrace{\mathrm{C}_{n} \mathrm{H}_{2 n+1}}_{1} \mathrm{Br}^{-} \\
& \text {1-alkylquinolinium }
\end{aligned}
$$

Figure 10. Some examples of anti-biofilm agents. ${ }^{[45]}$ and/or anion components that could facilitate antibiotic entry into the biofilm.

The pharmaceutical industry is currently paying more attention to ILs because they are customizable materials that can be specially tailored with selected characteristics by varying the combination of their cations and anions. This combination results in various ILs that can offer a wide range of hydrophobicity/hydrophilicity, acidity/basicity, viscosities, among other attributes. ${ }^{[39,48]}$

The arrangement of cations and anions with few possibilities for strong attractive intermolecular hydrogen bonding interactions decreases the potential for crystallization and provides facile access to pharmaceutically active ILs. ${ }^{[39,49]}$ This will naturally lead to ILs or salts that otherwise would not be explored if crystallization is the primary goal. One such example is the combination of a didecyldimethylammonium cation and saccharinate: the former is a cation with antimicrobial activity, and for this problem. An elucidative example is the case of lidocaine docusate, which combines the local surface anesthetic lidocaine cation with the hydrophobic anion, docusate (an emollient) to create a novel hydrophobic IL salt. This IL demonstrates decreased or controlled water solubility, and thus should exhibit extended residence time on the skin ${ }^{[17,39]}$ (Figure 11). The counterions are chosen by their inactive nature in order to give the desired physicochemical properties of a

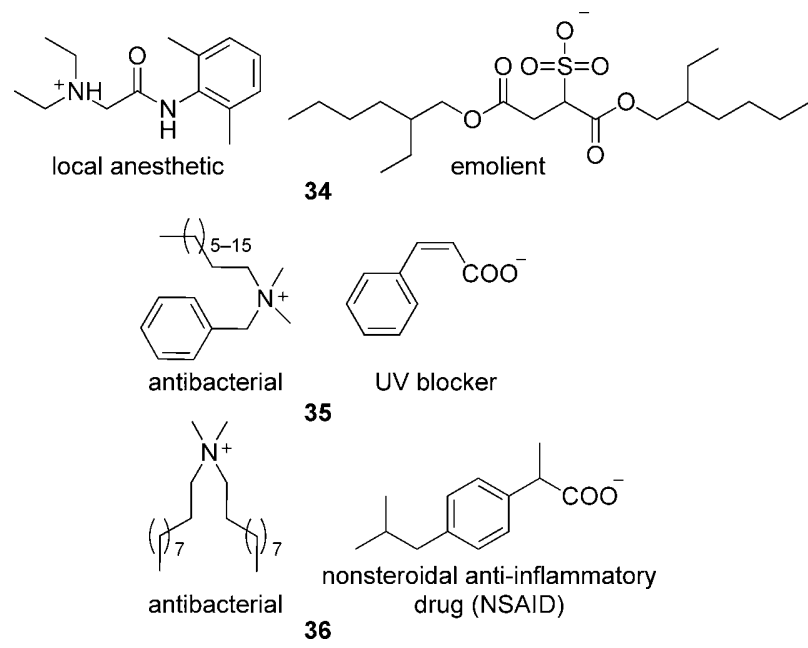

Figure 11. Examples of ILs with targeted biological properties combined with adequate selected physical and chemical properties. ${ }^{[1]}$

neutral drug. Recently, a small number of so-called "combination salts" have been prepared, including two active units (APIs) (compound 36, Figure 11) in the same singular compound coupled as a cation and an anion. ${ }^{[39,50]}$ In general this approach tends to be influenced by the need to obtain a crystalline material, or the fixed stoichiometry of active units found in such a crystalline salt. So called "dual functionality" has been explored as an important aspect of the IL field (for example, in dual acidic or double chiral ILs). ${ }^{[39,51]}$ In the context of APIs, 
Table 3. Antitumor activity $\left(\mathrm{Gl}_{50}[\mu \mathrm{M}]^{[\mathrm{ad}]}\right.$ and $\mathrm{LC}_{50}[\mu \mathrm{M}]^{[\mathrm{b}]}$ data) of compounds $26-\mathbf{3 0}$ (Figure 9) from five dose studies with the $\mathrm{NCl} 60$-cell-line ${ }^{[c]}$ screen from Kumar and Malhotra. ${ }^{[4]]}$

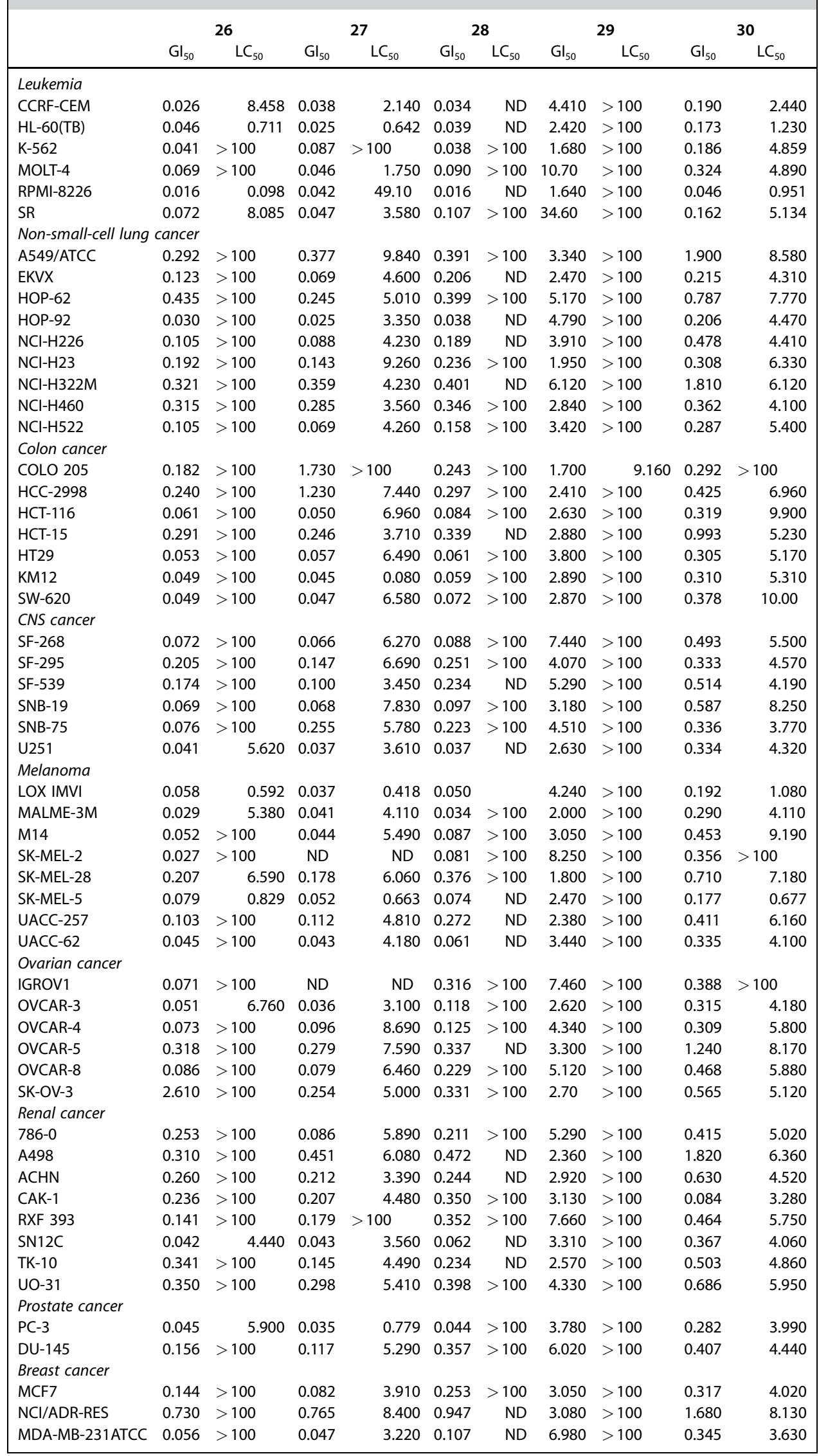

these kinds of studies open new avenues for exploration in pharmaceutical action.

Some examples of ILs composed of two biologically active ions were recently described in which both the cation and anion were selected based on the desired physical, chemical, and biological properties. ${ }^{[43]}$ Such ILs are frequently found as antimicrobials and disinfectants, ${ }^{[54]}$ for which the introduction of sweetness as a second functionality in the same formulation can be a desired factor for oral applications, such as mouthwashes.

In the context of APIs, a variety of approaches can be contemplated for which the two actives can be chosen. The counterions can be selected to synergistically enhance the desired effects or to neutralize unwanted side effects of the active entity. The counterion can also be chosen to pharmacologically act independently. ${ }^{[39,50]}$

In 2007 Pernak and co-workers patented a method for the preparation of ILs containing active pharmaceutical, biological, nutritional, and energetic ingredients. When a pharmaceutical activity is a desired property of the $\mathrm{IL}$, one or more of the ions in the disclosed IL composition can be a pharmaceutical ingredient $^{[55]}$ (Figure 12).

Importantly, a co-formation of two separate solid actives in a solid dosage form is significantly different from IL formulation. The ions from an IL will dissolve in bodily fluids in exactly the same way, as one ion cannot dissolve without the other. This is not true of separate solid forms administered at the same time, as each may dissolve at quite different rates. ${ }^{[39]}$ 


\begin{tabular}{|c|c|c|c|c|c|c|c|c|c|c|}
\hline & \multicolumn{2}{|r|}{26} & \multicolumn{2}{|c|}{27} & \multicolumn{2}{|c|}{28} & \multicolumn{2}{|r|}{29} & \multicolumn{2}{|r|}{30} \\
\hline & $\mathrm{Gl}_{50}$ & $\mathrm{LC}_{50}$ & $\mathrm{Gl}_{50}$ & $\mathrm{LC}_{50}$ & $\mathrm{Gl}_{50}$ & $\mathrm{LC}_{50}$ & $\mathrm{Gl}_{50}$ & $\mathrm{LC}_{50}$ & $\mathrm{Gl}_{50}$ & $\mathrm{LC}_{50}$ \\
\hline HS 578T & 0.053 & $>100$ & 0.077 & 9.390 & 0.084 & $>100$ & 1.760 & $>100$ & 0.417 & $>100$ \\
\hline MDA-MB-435 & 0.045 & 19.80 & 0.038 & 8.460 & 0.050 & $>100$ & 3.560 & $>100$ & 0.335 & 5.700 \\
\hline BT-549 & 0.066 & $>100$ & 0.061 & 4.370 & 0.094 & $>100$ & 3.100 & $>100$ & 0.421 & 4.420 \\
\hline $\mathrm{T}-47 \mathrm{D}$ & 0.073 & $>100$ & 0.068 & 20.40 & 0.089 & $>100$ & 1.150 & $>100$ & 0.428 & $>100$ \\
\hline MDA-MB-468 & 0.036 & 2.560 & 0.044 & 4.240 & 0.053 & $>100$ & 2.220 & $>100$ & 0.119 & 2.110 \\
\hline
\end{tabular}

[a] Drug concentration that results in a $50 \%$ decrease in net protein increase relative to control cells and toxicity. [b] Drug concentration lethal to $50 \%$ of cells; ND: not determined. [c] A 60-cell-line panel used as an in vitro substitute for the use of transplantable animal tumors in anticancer drug screening. ${ }^{[52]}$ and Drug Administration (FDA) is a major step forward in classifying the biopharmaceutical properties of drugs and drug products. Based on mechanistic approaches to the drug absorption and dissolution processes and intestinal permeability, the BCS enables regulatory bodies to simplify and improve the drug approval process. The knowledge of the BCS characteristics of a drug in a formula-

\begin{tabular}{|c|c|c|c|c|c|}
\hline \multirow[b]{2}{*}{ Organism } & \multirow[b]{2}{*}[\mathrm{mm}]{} & \multicolumn{4}{|c|}{$n$} \\
\hline & & 8 & 10 & 12 & 14 \\
\hline S. aureus & MIC & 722 & 40 & 18 & 16 \\
\hline ATCC 29213 & MBEC & 2708 & 2415 & 272 & 124 \\
\hline \multirow{2}{*}{ E-MRSA 15} & MIC & 722 & 40 & 18 & 16 \\
\hline & MBEC & 2708 & 1207 & 272 & 248 \\
\hline \multirow{2}{*}{ MRSA } & MIC & 1444 & 160 & 36 & 16 \\
\hline & MBEC & 21666 & 4829 & 545 & 124 \\
\hline S. epidermidis & MIC & 722 & 40 & 36 & 7.75 \\
\hline ATCC 35984 & MBEC & 10833 & 4829 & 272 & 124 \\
\hline E. coli & MIC & 722 & 321 & 73 & 33 \\
\hline NCTC 8196 & MBEC & 21666 & 9659 & 1089 & 124 \\
\hline P. aeruginosa & MIC & $5416^{[b]}$ & $2415^{[b]}$ & 580 & 264 \\
\hline PA01 & MBEC & 21666 & 2415 & 1089 & 496 \\
\hline K. aerogenes & MIC & 1444 & 643 & 73 & 33 \\
\hline NCTC 7427 & MBEC & 43331 & 19318 & 2179 & 248 \\
\hline B. cenocepacia & MIC & $>1444$ & 1287 & 290 & 132 \\
\hline$J 2315$ & MBEC & 43331 & 19318 & 2179 & 496 \\
\hline P. mirabilis & MIC & 1444 & 1287 & 580 & 264 \\
\hline NCTC 12442 & MBEC & 43331 & 9659 & 4357 & 1984 \\
\hline C. tropicalis & MIC & 1444 & 321 & 73 & 66 \\
\hline NCTC 7393 & MBEC & $>43331$ & 19318 & 8714 & 248 \\
\hline
\end{tabular}

[a] Antimicrobial agent concentration required to kill a microbial biofilm. ${ }^{[53]}[\mathrm{b}] \mathrm{MIC}$ values determined by the chemical bath deposition (CBD) method as per manufacturer's protocol, and defined as the lowest concentration of antibiotic at which a planktonic population could not be established by shedding of bacteria from a biofilm; ${ }^{[53]}$ the NCCLS [now the Clinical and Laboratory Standards Institute (CLSI)] method was not used; data are included for clarification and comparison only.

\section{Biopharmaceutics drug classification system (BCS)}

The development of drugs is always associated with standards and directives that also aid in drug classification. Biopharmaceutics is defined by the physical and chemical properties of a biologically active compound as well as the formulation and physiology of the route of administration. Nowadays, numerous molecules are classified through screening processes, and promising candidates are selected for additional in vitro and in vivo tests. At the end of the process, regulatory agencies make the ultimate authorization. ${ }^{[56]}$

The introduction of the biopharmaceutics drug classification system $(\mathrm{BCS})^{[57]}$ (Table 5) into the guidelines of the US Food

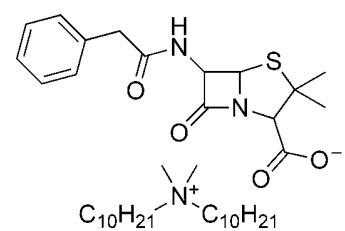

Didecyldimethylammonium Penicillin G

37<smiles>CCC[n+]1ccccc1</smiles><smiles>CCCC(CCC)C(=O)[O-]</smiles>

39

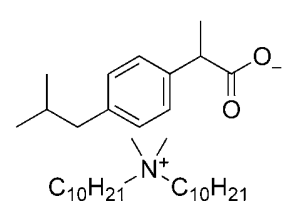

Didecyldimethylammonium Ibuprofen

38
Figure 12. Examples of an antibiotic (37), nonsteroidal anti-inflammatory agents/analgesics (38), and an antiepileptic agent (39) as ILs. ${ }^{[55]}$
Table 5. $\mathrm{BCS}^{[a]}$ classification of drugs and in vitro/in vivo correlation (IVIVC) expectations for immediate-release products based on the biopharmaceutics class, from Löbenberg and Amidon. ${ }^{[56]}$

\begin{tabular}{|c|c|c|c|}
\hline Class & Solubility & Permeability & IVIVC Expectation \\
\hline 1 & High & High & $\begin{array}{l}\text { IVIVC if the dissolution rate is slower than } \\
\text { the gastric emptying rate; otherwise, limit- } \\
\text { ed or no correlation. }\end{array}$ \\
\hline II & Low & High & $\begin{array}{l}\text { IVIVC expected if the in vitro dissolution } \\
\text { rate is similar to the in vivo dissolution } \\
\text { rate, unless the dose is very high. }\end{array}$ \\
\hline III & High & Low & $\begin{array}{l}\text { Absorption (permeability) is rate-determin- } \\
\text { ing and limited or no IVIVC with dissolu- } \\
\text { tion rate. }\end{array}$ \\
\hline IV & Low & Low & Limited or no IVIVC expected. \\
\hline
\end{tabular}

tion can also be used by formulation scientists to develop a more optimized dosage form based on fundamental mechanistic, rather than empirical, information. In this context the combination of the appropriate anion or cation with a drug could be a simple method to a pharmaceutical ingredient change in the BCS. 


\section{Some examples of ionic APIs}

There are numerous published examples in which pharmaceutically active compounds are salts of an active ion in combination with a relatively simple and inert counterion, or that can be easily transformed into cationic or anionic species. Table 6 illustrates some examples of drugs (or their APIs) that could be used for preparation of novel and pharmaceutically active ILs. The examples selected herein were listed in the 2009 Top-200 generic drug list by retail dollars. ${ }^{[58]}$ From the IL point of view, it is possible to use some examples from Table 6 as the cation unit, such as Omeprazole (rank 2), a drug used to treat gastroesophageal reflux disease, or the anion unit, such as the amoxicillin antibiotic (rank 9 and 28). Some of these possess dual functionalities, so they can be used as cation or anion, such as the antiepileptic Gabapentin (rank 8), or the angiotensin-converting enzyme inhibitor Lisinopril (rank 13), which is used for hypertension.

There are also numerous published examples of APIs in which both cation and anion are active pharmaceutical ingredients (Table 7). ${ }^{[50]}$ Following dissociation in solution, the cation and anion will each follow their independent kinetic and metabolic pathways.

\section{Conclusions and Future Perspectives}

The development of new synthetic strategies in organic chemistry using "eco-friendly" conditions is an issue of increasing interest. This leads to ILs, and has attracted the attention of the pharmaceutical industry. Naturally, further studies must be carried out in order to discover the full potential of their biomedical applications. The in-

Table 6. Examples of drugs (or their APIs) that could be used in ILs that are listed in the 2009 Top-200 generic drugs by retail dollars. ${ }^{[58]}$

Rank Drug ${ }^{[a]}$

Rank Drug ${ }^{[a]}$

2 Omeprazole: gastroesophageal reflux disease symptom treatment<smiles>COc1ccc2nc(S(=O)Cc3ncc(C)c(OC)c3C)[nH]c2c1</smiles>

$7 \quad$ Amlodipine besylate and benazepril: angiotensin-converting enzyme inhibitor

3 Metoprolol succinate: angiotensin-converting enzyme inhibitor<smiles>COCCc1ccc(OCC(O)CNC(C)C)cc1</smiles>

8 Gabapentin: antiepileptic and major depressive disorder treatment<smiles>CCOC(=O)C1=C(COCCN)NC(C)=C(C(=O)OC)C1c1ccccc1Cl</smiles>

9 Amoxicillin with potassium clavunate: antibiotic with $\beta$-lactamase inhibitor

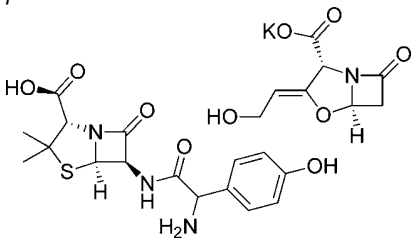

13

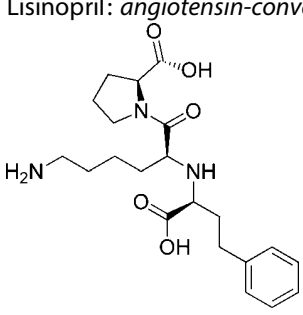

15 Lamotrigine: antiepileptic Cl<smiles>Nc1nnc(-c2cccc(Cl)c2Cl)c(N)n1</smiles>

17 Amlodipine besylate: angiotensin-converting enzyme inhibitor<smiles>CCOC(=O)C1=C(COCCN)NC(C)=C(C(=O)OC)C1c1ccccc1Cl</smiles>

21 Pantoprazole: gastroesophageal reflux disease symptom treatment

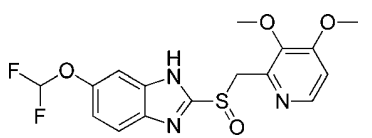

10 Fexofenadine: antihistaminic<smiles>CC(C)(C(=O)O)c1ccc(C(O)CCCN2CCC(C(O)(c3ccccc3)c3ccccc3)CC2)cc1</smiles>

14 Sumatriptan oral: antimigraine<smiles>CNS(=O)(=O)Cc1ccc2[nH]cc(CCN(C)C)c2c1</smiles>

16 Levothyroxine: hypothyroidism treatment<smiles>N[C@@H](Cc1cc(I)c(Oc2cc(I)c(O)c(I)c2)c(I)c1)C(=O)O</smiles>

18 Amphetamine: CNS stimulant
22 Cefdinir: antibiotic

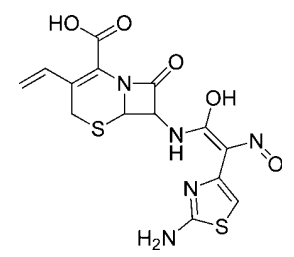


Table 6. (Continued)

Rank Drug ${ }^{[a]}$

24 Metformin: antidiabetic $\mathrm{NH} \mathrm{NH}$

党

26 Sertaline: antidepressant

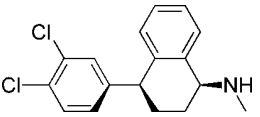

28

Amoxicillin: antibiotic

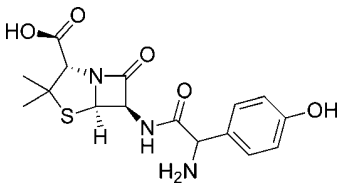

34 Fluoxetine: antidepressant<smiles>CNCCC(Oc1ccc(C(F)(F)F)cc1)c1ccccc1</smiles>

37 Alendronate: osteoporosis treatment

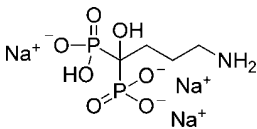

44 Clonazepam: anxiety disorder treatment<smiles>O=C1CN=C(c2ccccc2Cl)c2cc([N+](=O)[O-])ccc2N1</smiles>

46 Atenolol: beta blocker<smiles>CC(C)NCC(O)COc1ccc(CC(N)=O)cc1</smiles>

48 Lisinopril hydrochlorothiazide: angiotensin-converting enzyme inhibitor and diuretic

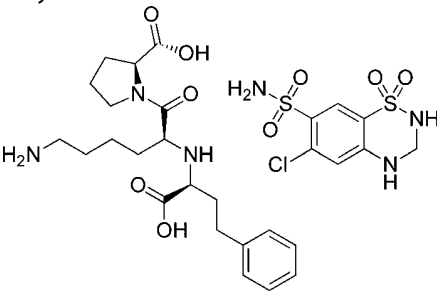

Rank Drug ${ }^{[a]}$

25 Divalproex sodium: antiepilectic<smiles>CCCC(CCC)C(=O)[O-]</smiles>

27 Budeprion XL: antidepressant<smiles>CNCCC(Oc1ccc(C(F)(F)F)cc1)c1ccccc1</smiles>

32 Bupropion XL: antidepressant<smiles>CC(NC(C)(C)C)C(=O)c1cccc(Cl)c1</smiles>

35 Pravastatin: HMG CoA reductase inhibito<smiles>CC[C@H](C)C(=O)O[C@H]1C[C@H](O)C=C2C=C[C@H](C)[C@H](CCC(O)CC(O)CC(=O)O)[C@]21C</smiles>

38 Topiramate: antiepileptic<smiles>CC1(C)OC2CO[C@]3(COS(N)(=O)=O)OC(C)(C)OC3[C@@H]2O1</smiles>

45 Hydrochlorothiazide: diuretic<smiles>NS(=O)(=O)c1cc2c(cc1Cl)NCNS2(=O)=O</smiles>

47 Paroxetine: antidepressant<smiles>Oc1ccc([C@@H]2CCNC[C@H]2COc2ccc3c(c2)OCO3)cc1</smiles>

50

Metoprolol tartrate: angiotensin-converting enzyme inhibitor

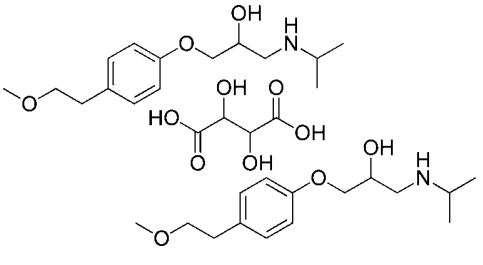

[a] The chemical structures of some compounds listed are rather simplified presentations of all functional groups present without analysis of acid-base reactions.

corporation of the IL approach into pharmaceuticals will continue to open new perspectives in industry and modern society. It is particularly important to emphasize that even slight modifications of an API can significantly change a drug's physical properties as well as its classification in the BCS. This approach can provide a platform to improve the pharmaceutical activity for new treatment options or even personalized medicine.

In summary, this Minireview highlights the very recent progress in the API-IL field, and demonstrates that ILs have the potential to impart an incredible degree of flexibility in the finetuning of physical, chemical and biological properties without covalent manipulation of the active units. Certainly there are associated challenges to bear in mind, including manufacture, scale-up, purification, stability, toxicity, and delivery, among others. However, the rush to obtain new drugs by molecular manipulation and discovery may have obscured the fact that many known drugs could be manipulated into more effective species by simple salt chemistry-albeit a salt chemistry unlike any other yet attempted by the industry. For that reason, the liquid state by itself should not be overlooked, but should be considered as an alternative to common solid-state techniques. In this context, new possibilities, challenges, and thrilling opportunities might be the reward.

Keywords: drugs • ionic liquids - pharmaceutical activity medicinal chemistry

[1] S. Zhang, X. Lu, Q. Zhou, X. Li, X Zang, S. Li, lonic Liquids: Physicochemical Properties, Elsevier, Amsterdam, 2009.

[2] S. Sowmiah, V. Srinivasadesikan, M.-C. Tseng, Y.-H. Chu, Molecules 2009, 14, 3780-3813.

[3] D. R. MacFarlane, K. R. Seddon, Aust. J. Chem. 2007, 60, 3-5.

[4] T. Torimoto, T. Tsuda, K. Okazaki, S. Kuwabata, Adv. Mater. 2010, 22, $1196-1221$

[5] D. R. MacFarlane, J. M. Pringle, K. M. Johansson, S. A. Forsyth, M.

Forsyth, Chem. Commun 2006, 1905-1917.

[6] R. D. Rogers, G. A. Voth, Acc. Chem. Res. 2007, 40, 1077-1078.

[7] P. Wasserscheid, T. Welton, lonic Liquids in Synthesis, Wiley- $\mathrm{VCH}$, Weinheim, 2007.

[8] M. Freemantle, Chem. Eng. News 1998, 76 (13), 32-37.

[9] D. B. Zhao, M. Wu, Y. Kou, E. Min, Catal. Today 2002, 74, 157-189. 
Table 7. Examples of ionic liquid salt pairs with both cation and anion as active components; data from Kumar and Malhotra. ${ }^{[50]}$

$\begin{array}{ll}\text { Cation } & \text { Anion } \\ \text { sic, anti-inflammatory, antipyretic } & \begin{array}{l}\left.\text { Gentisic acid: (mp: } 200-205^{\circ} \mathrm{C}\right) \\ \text { pyretic }\end{array}\end{array}$

Didecyldimethylammonium: anti- Ibuprofenate: anti-inflammatory bacterial

$\mathrm{C}_{10} \mathrm{H}_{21}-\mathrm{N}^{+} \mathrm{C}_{10} \mathrm{H}_{21}$

Benzalkonium: antibacterial

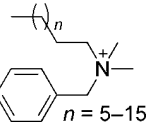

Benzalkonium: antibacterial

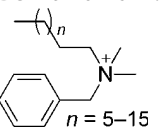<smiles>CC(C)Cc1ccc(C(C)C(=O)O)cc1</smiles>

Colawet MA-80: wetting agent<smiles>CCCCOC(=O)C(CC(=O)OCCO)C(=O)OCCCCO</smiles>

Sulfacetamide: anti-acne

住

Ranitidine: histamine $\mathrm{H} 2$ receptor Docusate: emollient antagonist

$\underbrace{+1}_{2}$
Salt Pair

Phenazone gentisate (mp: $87-88^{\circ} \mathrm{C}$ )

analgesic, anti-inflammatory, antipyretic $^{[59]}$

Benzalkonium ibuprofenate:

(mp: $-41^{\circ} \mathrm{C}^{[60]}$ )

Didecyldimethyl ammonium ibuprofenate: (mp: liquid at $\mathrm{RT}^{[17]}$ )

Benzalkonium colawet MA-80 (mp: liquid at $\mathrm{RT}^{[60]}$ )

Benzalkonium sulfacetamide:

Ranitidine docusate $\mathrm{e}^{[17]}$ (mp: liquid at $\mathrm{RT}^{[60]}$ )

[24] a) F. H. Hurley, T. P. Wier, J. Electrochem. Soc. 1951, 98, 203-206 b) F. H. Hurley, T. P. Wier, J. Electrochem. Soc. 1951, 98, 207-212.

[25] R. J. Gale, B. Gilbert, R. A. Osteryoung, Inorg. Chem. 1978, 17 2728- 2729.

[26] a) S. Christie, R. H. Dubois, R. D. Rogers, P. S. White, M. J. Zaworotko, J. Inclusion Phenom. Mol. Recognit. Chem. 1991, 11, 103-114 b) J. M. Martell, M. J. Zaworotko, J. Chem. Soc. Dalton Trans. 1991 1495-1498; c) J. S. Wilkes, M. J. Zaworotko, J. Chem. Soc. Chem. Commun. 1992, 965-967.

[27] a) J. Fuller, R. T. Carlin, J. Chem. Crystallogr. 1994, 24, 489-493. b) J. Fuller, R. T. Carlin, H. C. Delong, D. Haworth, J. Chem. Soc Chem. Commun. 1994, 299-300.

[28] H. Mizuuchi, V. Jaitely, S. Murdan, A. T. Florence, Eur. J. Pharm. Sci. 2008, 33, 326-331.

[29] a) V. Jaitely, A. Karatas, A. T. Florence, Int. J. Pharm. 2008, 354, 168-173; b) M. Moniruzzaman, N. Kamiya, M. Goto, J. Colloid Interface Sci. 2010, 352, 136-142 c) M. Moniruzzaman, M. Tamura, Y. Tahara, N. Kamiya, M. Goto, Int. J. Pharm. 2010, 400, 243-250; d) L. Viau, C. Tourné-Péteilh, J.-M. Devoisselle, A. Vioux, Chem Commun. 2010, 46, 228-230.

[30] H. Rodriguez, K. Bica, R. D. Rogers, Trop. J. Pharm. Res. 2008, 7, $1011-$ 1012

[31] S. N. Black, E. A. Collier, R. J. Davey, R. J. Roberts, J. Pharm. Sci. 2007, 96, $1053-1068$.

[10] M. J. Earle, K. R. Seddon, Pure Appl. Chem. 2000, 72, 1391 - 1398.

[11] a) M. Haumann, A. Riisager, Chem. Rev. 2008, 108, 1474-1497; b) W. S. Miao, T. H. Chan, Acc. Chem. Res. 2006, 39, 897-908.

[12] a) X. Han, D. W. Armstrong, Acc. Chem. Res. 2007, 40, 1079-1086; b) J. G. Huddleston, H. D. Willauer, R. P. Swatloski, A. E. Visser, R. D. Rogers, Chem. Commun. 1998, 1765-1766.

[13] a) P. Hapiot, C. Lagrost, Chem. Rev. 2008, 108, 2238-2264; b) D. R. Macfarlane, M. Forsyth, P. C. Howlett, J. M. Pringle, J. Sun, G. Annat, W. Neil, E. I. Izgorodina, Acc. Chem. Res. 2007, 40, 1165-1173.

[14] a) T. Ichikawa, M. Yoshio, A. Hamasaki, T. Mukai, H. Ohno, T. Kato, J. Am. Chem. Soc. 2007, 129, $10662-10663$; b) K. Biswas, C. N. R. Rao, Chem. Eur. J. 2007, 13, 6123-6129.

[15] F. van Rantwijk, R. A. Sheldon, Chem. Rev. 2007, 107, 2757-2785.

[16] a) T. L. Greaves, C. J. Drummond, Chem. Rev. 2008, 108, 206-237; b) S. Schneider, T. Hawkins, M. Rosander, G. Vaghjiani, S. Chambreau, G. Drake, Energy Fuels 2008, 22, $2871-2872$.

[17] W. L. Hough, M. Smiglak, H. Rodriguez, R. P. Swatloski, S. K. Spear, D. T. Daly, J. Pernak, J. E. Grisel, R. D. Carliss, M. D. Soutullo, J. H. Davis, R. D. Rogers, New J. Chem. 2007, 31, 1429-1436.

[18] M. Deetlefs, K. R. Seddon, M. Shara, Phys. Chem. Chem. Phys. 2006, 8, $642-649$.

[19] J. D. Holbrey, K. R. Seddon, Clean Technol. Environ. Policy 1999, 1, $223-$ 236

[20] M. J. Earle, P. B. McCormac, K. R. Seddon, Green Chem. 2000, 2, 261 262

[21] E. B. Carter, S. L. Culver, P. A. Fox, R. D. Goode, I. Ntai, M. D. Tickell, R. K. Traylor, N. W. Hoffman, J. H. Davis, Chem. Commun. 2004, 630-631.

[22] J. Pernak, K. Sobaszkiewicz, I. Mirska, Green Chem. 2003, 5, 52-56.

[23] J. S. Wilkes, Green Chem. 2002, 4, 73-80.
[32] B. D. Anderson, R. A. Conradi, J. Pharm. Sci. 1985, 74, 815-820.

[33] M. L. Peterson, M. B. Hickey, M. J. Zaworotko, O. Almarsson, J. Pharm. Pharm. Sci. 2006, 9, 317-326.

[34] a) S. L. Morissette, Ö. Almarsson, M. L. Peterson, J. F. Remenar, M. J. Read, A. V. Lemmo, S. Ellis, M. J. Cima, C. R. Gardner, Adv. Drug Delivery Rev. 2004, 56, 275-300; b) D. Singhal, W. Curatolo, Adv. Drug Delivery Rev. 2004, 56, 335-347.

[35] S. Datta, D. J. W. Grant, Nat. Rev. Drug Discovery 2004, 3, 42-57.

[36] J. Bauer, S. Spanton, R. Henry, J. Quick, W. Dziki, W. Porter, J. Morris, Pharm. Res. 2001, 18, 859-866.

[37] A. T. Hulme, S. L. Price, D. A. Tocher, J. Am. Chem. Soc. 2005, 127, 1116 1117

[38] A. Brodin, A. Nyqvistmayer, T. Wadsten, B. Forslund, F. Broberg, J. Pharm. Sci. 1984, 73, $481-484$.

[39] J. Stoimenovski, D. R. MacFarlane, K. Bica, R. D. Rogers, Pharm. Res 2010, 27, $521-526$

[40] W. M. Reichert, J. D. Holbrey, K. B. Vigour, T. D. Morgan, G. A. Broker, R. D. Rogers, Chem. Commun. 2006, 4767-4779.

[41] D. R. MacFarlane, S. A. Forsyth, J. Golding, G. B. Deacon, Green Chem. 2002, 4, 444-448.

[42] a) J. Ranke, S. Stolte, R. Stormann, J. Arning, B. Jastorff, Chem. Rev. 2007 107, 2183-2206; b) A. Cornellas, L. Perez, F. Comelles, I. Ribosa, A. Manresa, M. T. Garcia, J. Colloid Interface Sci. 2011, 355, 164-171; c) S. M. Saadeh, Z. Yasseen, F. A. Sharif, H. M. Abu Shawish, Ecotoxicol. Environ. Saf. 2009, 72, $1805-1809$.

[43] W. L. Hough-Troutman, M. Smiglak, S. Griffin, W. M. Reichert, I. Mirska, J. Jodynis-Liebert, T. Adamska, J. Nawrot, M. Stasiewicz, R. D. Rogers, J. Pernak, New J. Chem. 2009, 33, 26-33.

[44] D. Demberelnyamba, K. S. Kim, S. J. Choi, S. Y. Park, H. Lee, C. J. Kim, I. D. Yoo, Bioorg. Med. Chem. 2004, 12, 853-857. 
[45] L. Carson, P. K. W. Chau, M. J. Earle, M. A. Gilea, B. F. Gilmore, S. P. Gorman, M. T. McCann, K. R. Seddon, Green Chem. 2009, 11, 492-497.

[46] V. Kumar, S. V. Malhotra, Bioorg. Med. Chem. Lett. 2009, 19, 4643-4646.

[47] J. Pernak, J. Feder-Kubis, Chem. Eur. J. 2005, 11, $4441-4449$.

[48] R. D. Rogers, K. R. Seddon, Science 2003, 302, 792-793.

[49] P. M. Dean, J. Turanjanin, M. Yoshizawa-Fujita, D. R. MacFarlane, J. L. Scott, Cryst. Growth Des. 2009, 9, 1137-1145.

[50] V. Kumar, S. V. Malhotra in Ionic Liquid Applications: Pharmaceuticals, Therapeutics, and Biotechnology, American Chemical Society, Washington DC, 2010, pp. 1-12.

[51] Z. F. Fei, T. J. Geldbach, D. B. Zhao, P. J. Dyson, Chem. Eur. J. 2006, 12 $2122-2130$.

[52] R. H. Shoemaker, Nat. Rev. Cancer 2006, 6, 813-823.

[53] M. E. Olson, H. Ceri, D. W. Morck, A. G. Buret, R. R. Read, Can. J. Vet. Res. 2002, 66, 86-92.

[54] L. S. C. Wan, J. Pharm. Sci. 1968, 57, 1903-1906.

[55] a) R. Rogers, D. T. Daly, R. P. Swatloski, W. L. Hough, J. H. Davis, M. Smiglak, J. Pernak, S. K. Spear, WO2007044693, 2007; b) R. Rogers, D. T.
Daly, G. Gurau, D. MacFarlane, J. Turanjanin, P. Dean, J. L. Scott, K. Bica, K. Seddon, WO2010078300 (A1), 2010; c) K. Bica, C. Rijksen, M. Nieuwenhuyzen, R. D. Rogers, Phys. Chem. Chem. Phys. 2010, 12, $2011-2017$.

[56] R. Löbenberg, G. L. Amidon, Eur. J. Pharm. Biopharm. 2000, 50, 3-12.

[57] G. L. Amidon, H. Lennernäs, V. P. Shah, J. R. Crison, Pharm. Res. 1995, 12, 413-420.

[58] Drug Topics: http://drugtopics.modernmedicine.com/drugtopics/data/ articlestandard//drugtopics/252010/674976/article.pdf (accessed April 7, 2011).

[59] M. Hoffer, N. J. Nutley, US 2541651, 1951.

[60] W. L. Hough, R. D. Rogers, Bull. Chem. Soc. Jpn. 2007, 80, 2262-2269.

Received: February 10, 2011

Revised: March 18, 2011

Published online on May 9, 2011 